\title{
Why European Subordinates Trust their Managers
}

\author{
Jon Aarum Andersen ${ }^{1}$, Jure Kovač ${ }^{2}$ \\ ${ }^{1}$ Lillehammer University College, N-2604 Lillehammer, PO Box 952, Norway, Jon.Andersen @ hil.no \\ ${ }^{2}$ University of Maribor, Faculty of Organizational Sciences, Kidričeva cesta 55a, 4000 Kranj, Slovenia, \\ Jure.Kovac@fov.uni-mb.si
}

\begin{abstract}
This article addresses the problem of why subordinates trust their managers based on the responses from 108 subordinates of seven Slovenian managers and from 138 subordinates of eight Swedish managers. The subordinates of these managers responded to a 20-item instrument tested for reliability and validity. In both samples the managers enjoyed different degrees of trust. The level of trust vested in Slovenian managers was higher than in Swedish ones. The kinds of managers' actions that enhanced trust were similar amongst Swedish and Slovenian subordinates. Different socio-cultural contexts may theoretically explain why some other kinds of actions had contrasting effects between the samples. On the whole, the actions of managers explain trust in both countries. Subordinates' trust in managers declines with the increasing hierarchical distance in both national samples. Managers need to show in action that they trust their subordinates, promote their interests, demonstrate appreciation of their subordinates, and solve problems.
\end{abstract}

Key words: Trust, managers, subordinates, societal factors, hierarchy

\section{Introduction}

This comparative study addresses the problem of why subordinates trust their managers. It specifically addresses the questions of how trust can be developed, but not the consequences of trust and distrust. On the basis of a review of contemporary research on trust, Rousseau et al. (1998) have defined trust as a psychological state comprising the intention to accept vulnerability based upon positive expectations of the intention or action of another. This present study has applied this definition. Dirks and Ferrin (2002) make a distinction between trust in a direct leader (manager) and trust in organizational leadership (management). This study is only concerned with trust in a direct manager, that is, the superior person of the subordinates.

The literature review shows that few studies have addressed the reasons for trust between subordinates and managers, and empirical studies on this relationship are scant. Ferrin and Gillespie (2010) have claimed that it is critical and timely to consider whether and how national or societal culture influences interpersonal trust. We also need to understand whether socio-cultural characteristics influence the trust that managers enjoy from their subordinates. This comparative study with data from Sweden and Slovenia indicates that
Swedish subordinates do not trust their managers as much as their Slovenian counterparts do. A degree of similarity was found regarding what kinds of managers' actions enhanced trust in Sweden and Slovenia. The different socio-cultural contexts may theoretically explain why some other kinds of actions had contrasting effects on the subordinates. The term socio-cultural context refers here primarily to the cultural dimensions of Hofstede (1991) especially the dimensions of power-distance and uncertainty-avoidance. Trust is induced through actions, but the reasons for trust may vary owing to socio-cultural factors. Subordinates' trust in managers declines with increasing hierarchical distance.

\section{Theories on trust in managers}

Few studies have actually addressed the reasons for trust between subordinates and managers. The question of the reasons for trust is distinct both from the consequences of trust (e.g., Poon, 2006) and from the effects of trust violation and erosion (Elangovan et al., 2007). The present study also differs from the work of Atkinson and Butcher (2003) on the development of trust in the context of managerial relationships and the political realities of organizational life.

Received: $2^{\text {nd }}$ July 2012; revised $2^{\text {th }}$ September 2012; accepted $27^{\text {th }}$ September 2012 
The role of trust between managers and their subordinates has been the subject of research from numerous different disciplines. Trust is a crucial element in the behaviour effective leadership (Fleishman and Harris, 1962; Bass, 1990). Other researchers have shown that managers' efforts to build trust involve key mechanisms for enhancing organizational effectiveness (Barney and Hansen, 1994; Dirks, 2000; Dirks and Ferrin, 2002; Morgan and Zeffane, 2003; Bijlsma et al., 2008). Furthermore, Bijlsma-Frankema et al. (2008) have concluded that trust in supervisors is an important factor in promoting team performance. Drawing from these observations, we may conclude that trust in superiors is advantageous for both individuals and organizations.

A number of scholars have insisted on the need to appreciate the role of actions and behaviours in order to understand the phenomenon of trust (Sitkin and Roth, 1993; Gambetta, 1988; Luhmann, 1988; Coleman, 1990; Sheppard and Sherman, 1998). Bhattacharya et al. (1998) have concluded that trust is not only dependent on actions but also on outcomes and consequences. Trust, then, is a condition for interaction between individuals (Seligman, 1997). Whitener et al. (1998) have identified a series of managerial behaviours that may affect employees' trust in managers. Dirks (2000) has also studied how trust can be built through the actions of the managers. Biljsma and van de Bunt (2003) have found four managerial actions which generate trust amongst subordinates.

Additionally, globalization introduces a need to understand the role of socio-cultural contexts of trust in workplaces. With this consideration in mind, this study concentrates on subordinates' trust in managers and asks whether subordinatemanager relationships vary with societal and national characteristics. In order to address this question, this study has sought to compare the data from a Swedish study (Andersen, 2005) with data from another country, and preferably one with markedly different socio-cultural characteristics for testing the robustness of the conclusions. Data from a Slovenian organization, therefore, appeared to be apposite for this comparative study.

The Swedish study has shown that managers enjoyed different degrees of trust. Additionally, the managers' actions and support create trust, and explain the subordinates' trust in them. Two specific problems addressed here are (1) whether these conclusions on trust in managers based on a Swedish study are valid for Slovenian managers, and (2) whether aspects of trust are dependent on societal characteristics.

\section{Hypotheses}

Andersen (2005) has found that Swedish managers enjoyed different degrees of trust from their subordinates. It was imperative, then, to establish whether or not this is the case for managers in Slovenia. If managers from the two countries enjoy the same degree of trust as each other, then the issue of trust is inconsequential.

\section{H1: Managers enjoy different degrees of trust.}

Bijlsma-Frankema (2000) has suggested 38 explanations for subordinates' trust in their managers. Dirks and Skarlicki
(2004) have also noted that trust in leadership appears to be associated with a well-established set of leadership actions and behaviours. "Leaders generate and sustain trust [ ... ] through the behavior of the leader", according to Joseph and Winston (2005, p. 7). Dirks and Ferrin (2002, p. 614) claim that individuals observe leaders' actions and draw inferences about the nature of the relationship with the leaders or the character of the leader, or both. The analyses performed by Andersen (2005) have indicated that managers' actions as perceived by the subordinates create trust. One purpose of the present study is to explore the validity of this explanation in Slovenia.

Processes of globalization have, moreover, accelerated the introduction of comparable managerial practices into different environments. Ferrin and Gillespie (2010) have claimed that it is critical and timely to consider whether and how national or societal culture influences interpersonal trust. We also need to understand whether socio-cultural characteristics influence the trust that managers enjoy from their subordinates. Globalization draws attention to the need to understand what socio-cultural influences there may be on trust in organizations, and whether the trust that managers enjoy from their subordinates depends on these factors. Lämsä and Pucetaite (2006) have pointed out that little research has been done to understand this relationship. There may be significant differences in values and work cultures across nations. Work morale, for instance, is an important factor in the development of trust amongst employees in some societies (Wicks and Berman, 2004).

Doney et al. (1998) have proposed a conceptual framework for studying trust in which Hofstede's cultural dimensions were included. The formulation of the second hypothesis has also taken into account Hofstede's theoretical concept, which links the characteristics of managerial styles with the cultural environment (Hofstede, 1991; Wade, 2003). The purpose of testing the second hypothesis is to find out whether Andersen's conclusion (2005) that trust in managers has it basis on managers' behaviour is valid in a Slovenian company or not. Consequently, the second hypothesis is:

H2: The reasons for subordinates' trust in managers are independent of socio-cultural contexts.

Trust is based on information and personal judgement (Mayer et al., 1995). More specifically, information on the personal qualities and social limitations of others is vital (Gambetta, 1988). Bigley and Pearce (1998) have pointed out that problems also arise in interactions between actors acquainted with each other in an ongoing relation. Subordinates' trust in their managers is partly a product of their ability to judge their managers' reliability (Sheppard and Sherman, 1998). It is assumed that some subordinates have a better basis for judging the reliability of their managers owing to daily and close contact. Other subordinates will not have the same knowledge of their manager and his or her behaviour. Dirks and Ferrin (2002) also emphasize the effect of the hierarchical distance.

Andersen (2005) has found that trust in managers is significantly higher for those subordinates with closer proximity to the manager. It is worthwhile, then, to explore this relationship with data from a Slovenian sample, as neither 
theoretical arguments nor empirical studies indicate that sociocultural factors influence this relationship. In this regard, data from House et al. (2004) on power distance may be relevant. Slovenia ranked higher than Sweden, band A and band B, respectively. This result is in line with data from Hofstede and Hofstede (2004), who also reported that the power distance is higher in Slovenia than in Sweden. The purpose of testing the third hypothesis is to find out whether the finding of Andersen (2005) that trust in managers differs according to the subordinates' hierarchical level is independent of societal factors.

H3: Subordinates' trust in managers declines with increasing hierarchical distance.

\section{Empirical study of trust in managers in Sweden and Slovenia}

\section{Sample}

The Slovenian and the Swedish companies were almost identical with respect to such parameters as the number of hierarchical levels and the number of organizational units. Additionally, the position of the managers in this study was virtually identical, most being production managers. Both were manufacturing companies and part of large groups of companies. The Slovenian company employed 781 people who were organized into five large production units. The Swedish and Slovenian companies differed in the number of managers on the secondary level: the Swedish company had eight managers, whilst the Slovenian company had seven. No data had been collected on the age and sex of the respondents and their managers. All managers were male and very few of the subordinates were female.

\section{Response}

The number of respondents in Sweden in 2003 was 138, and in Slovenia 108. In Sweden, 44 people were in a directly subordinate position (closest subordinates of the managers), and 94 were classified as other employees. Some subordinates have a better basis for judging the trustworthiness of their managers because of their daily and close contact with the managers. In this study "closeness between subordinates and managers" refers to staff personnel who directly report to the managers and meet, see, and work with the managers on a daily basis as well as with next-level managers who also frequently interact with the managers in question. In Slovenia, 51 of the surveyed people were directly subordinate ( 25 of those were close co-workers), and 57 were other employees. In the Swedish research, the response rate varied between 50 per cent and 92 per cent. The response rate in Slovenia varied between 70 per cent and 100 per cent. Table 2 shows the main features of the two samples.

\section{Instrument}

Andersen (2005) has performed a study of trust in managers in a Swedish manufacturing company with 590 employees that focused on trust in eight managers, including the managing director. The investigations were carried out in 2002 and 2003. The study in 2002 utilized a questionnaire that was hypothesized to explain the degree of trust with 38 items of independent variables. An exploratory factor analysis showed that the 38 items formed three factors with a total of 20 items, which showed a high degree of internal consistency. The study was replicated in 2003 with the same eight managers and their closest subordinates, as well as all subordinates of one of the production managers. The study performed in 2003 used a refined version of the questionnaire with 21 items (including the dependent-variable item). In both the Swedish and Slovenian studies, the subordinates received the questionnaire at their home address, and they returned it directly to the researchers.

\section{Reliability and validity of instrument applied}

A questionnaire, based on previous research measured trust and its hypothesized causes, used a five-point Likert scale for all items (Andersen, 2005). The questionnaires used in the Swedish investigation in 2003 and in Slovenia in 2006 were identical. The original items in English were translated into Swedish and Slovenian and subjected to back-translations.

\section{Reliability - Cronbach's alpha}

To assess the reliability of the respondents' choice of individual statements, this study applied a Cronbach's alpha test. Table 1 summarizes the answers of the 44 respondents directly subordinated to all managers and the 94 other employees in the Swedish study, and the 51 respondents directly subordinated to all managers (of which 25 were close coworkers), and the 57 other employees in the Slovenian study. In the Swedish and Slovenian studies all three factors showed a very high degree of internal consistency according to Cronbach's alpha. It is a generally agreed that a value higher

Table 1. Cronbach's a per factor - Sweden $(N=138)$ and Slovenia $(N=108)$

\begin{tabular}{lccccccc}
\hline & \multicolumn{2}{c}{ No. of items } & \multicolumn{2}{c}{$\alpha$} & \multicolumn{3}{c}{ Standardized item $\alpha$} \\
\cline { 2 - 7 } Factor & Sweden & Slovenia & Sweden & Slovenia & Sweden & Slovenia \\
\hline 1: Improvements & 8 & 5 & 0.87 & 0.84 & 0.87 & 0.83 \\
2: Managers' actions & 8 & 8 & 0.94 & 0.83 & 0.94 & 0.89 \\
3: Goals & 4 & 4 & 0.79 & 0.80 & 0.79 & 0.80 \\
\hline
\end{tabular}


Table 2. Overview of samples and response rates

\begin{tabular}{lcc}
\hline Sample characteristics & Sweden & Slovenia \\
\hline Number of managers & 8 & 7 \\
All managers - No. of closest subordinates & 44 & 25 \\
All managers - No. of subordinates reporting directly & NA & 26 \\
All managers - No. of remote subordinates & NA & 57 \\
One manager - No. of remote employees & 94 & NA \\
Total number of respondents & 138 & 108 \\
Response rate (average) & $80 \%$ & $82 \%$ \\
Total number of employees & 590 & 781 \\
\hline
\end{tabular}

than 0.70 is necessary to affirm reliability with Cronbach's alpha (Bagozzi, 1994; Nunally, 1978).

\section{Validity}

The studies of Bijlsma-Frankema $(2000,2002)$ have provided a theoretical basis for each affirmative statement on the questionnaire. The questionnaire items were generated from interviews with managers and subordinates. The performed factor analysis has revealed both discriminate and convergent validity.

These studies regarded trust as a quantitative variable, and they measured trust rather than distrust. The affirmative statement of "I trust my manager" measured the dependent variable of trust (item no. 4). In order to perform a more demanding statistical analysis, an assessment of whether the dependent variable trust has a normal distribution was necessary. The average values of the dependent variable and its standard deviation (with skewness and kurtosis- values less than one) for both the Swedish and Slovenian samples made it reasonable to regard trust as having a normal distribution (table 3). The variable had close to normal distribution. The requirements for performing the statistical analyses were met, therefore. The analysis showed that trust is a matter of degree. It appeared reasonable, then, to treat trust as a quantitative, continuous variable.

\section{Analyses}

Testing hypothesis one: Managers enjoy different degrees of trust.

At the outset, both the Swedish and the Slovenian data show that managers enjoy different degrees of trust from their subordinates. Table 3 supports the first hypothesis. Trust vested in Slovenian managers was higher than trust given to Swedish managers by their subordinates. A t-test of the two samples informed that the difference between the average trust was significant, with $\mathrm{t}=4.633, \mathrm{p}<0.05$.

These findings of the average degree of trust (mean) and standard deviation in Sweden and Slovenia can be compared with the findings of Elangovan et al. (2007), who reported 4.43 and $0.61(\mathrm{~N}=120)$ with samples from Austria and Germany, and Poon (2006), who with data from Malaysia reported 3.38 and $0.71(\mathrm{~N}=106)$ by using different instruments. Ferrin and Gillespie (2010) have concluded that there is robust support for the view that there are meaningful differences across countries in the average level of generalized trust.

Data on socio-cultural factors and national characteristics has not been collected. What has been done is to refer to other scholars' work, particularly Hofstede (1991) and Hofstede and Hofstede (2004). These factors are used to explain our findings theoretically, not to show that they empirically do so.

Table 3. Mean degree of trust per manager - Sweden $(N=138) v$ s. Slovenia $(N=108)$

\begin{tabular}{lcccccccc}
\hline & \multicolumn{7}{c}{ Manager no. } \\
\cline { 2 - 8 } Trust mean & 1 & 2 & 3 & 4 & 5 & 6 & 7 & 8 \\
\hline Sweden = 3.25 (1.24) & 4.5 & 4.3 & 3.8 & 3.6 & 3.4 & 2.7 & 2.4 & 2.0 \\
Slovenia = 3.93 (1.09) & 4.1 & 4.1 & 4.1 & 3.9 & 3.9 & 3.3 & 3.3 \\
\hline
\end{tabular}

Note: Standard deviation in brackets. 
What may be the theoretically explanation for the significant difference in trust between Slovenian and Swedish managers?

In both Sweden (population 9.5 million) and Slovenia (population 2 million) the manufacturing industry is the most important. It is quite common to group Sweden as a Northern European or Nordic country. Placing Slovenia in the Eastern European cluster is, however, quite imprecise. Even when it was a part of the former Yugoslavia, Slovenia was the least influenced by the communist regime and was the most affluent and industrialized part.

Data from the European Values Survey (1999-2000) (Halman, 2003) have shown that work is more important to Slovenians than to Swedes. The power-distance index measures the extent to which the less powerful employees of organizations accept and expect the unequal distribution of power (Hofstede, 1991). It suggests that the followers endorse a society's level of inequality as much as the leaders do. The uncertainty-avoidance index indicates the degree to which people feel threatened by ambiguity or unknown situations. Slovenia ranked 15th and Sweden ranked 70th on this variable (Hofstede and Hofstede, 2004). If trust is a solution to countering uncertainty and risk, then differences in the degree of uncertainty avoidance between the two countries may account for differences in the degree of trust given to superiors. Previous studies suggest that the general level of trust is higher in Slovenia than in Sweden (Hofstede and Hofstede, 2004; Rus and Iglič, 2005; van Deth et al., 2007). According to the Edelman Trust Barometer (2009), the Slovenians' trust in management is higher than the Swedes'. If trust is a solution to countering uncertainty and risk, then differences in the higher degree of uncertainty avoidance in Slovenia may account for a higher degree of trust given to Slovenian superiors. This may explain why the trust vested in Slovenian managers was higher than the trust given to Swedish managers.

Testing hypothesis two: The reasons for subordinates' trust in managers are independent of socio-cultural contexts.

\section{Factor analyses}

The factor analyses included all 20 independent variables from the Swedish study and the same items from the Slovenian study. The result of the factor analyses of both studies is shown in table 1. Both the Swedish and Slovenian factor analyses yielded three factors: (1) improvements, working conditions, and atmosphere; (2) managers' actions and support; and (3) goals, development, and achievements. The items resulting from the factor analyses are shown in tables 4, 5, and 6 .

The importance of mutual trust captured by item 2 (I feel that the manager trusts me) is also emphasized by Atkinson (2004), who stresses that there is an element of interdependence between subordinates' trust in their managers and sub-

Table 4. Factor 1: Improvements, working conditions, and atmosphere

\begin{tabular}{ll}
\hline Sweden (2003) & Slovenia (2006) \\
\hline $\begin{array}{l}\text { Item 11: The manager provides for conditions that make the } \\
\text { goals set for my team/, unit/, department/, company attain- } \\
\text { able. (0.67) }\end{array}$ & $\begin{array}{l}\text { Item 11: The manager provides for conditions that make the } \\
\text { goals set for my team/, unit/, department/, company attain- } \\
\text { able. (0.76) }\end{array}$
\end{tabular}

Item 14: Responsibilities are clearly demarcated in this department/, company. (0.67)

Item 20: There are enough resources at my disposal to fulfil my tasks. (0.78)

Item 1: Ideas and suggestions for improvement of work processes are quickly implemented in this department, company. (0.71)

Item 5: Differences of opinion between people are cleared up in an open and honest way around here. (0.70)

Item 8: In this department/ company, employees are treated with care. (0.69)

Item 16: My manager quickly implements our ideas for the improvement of work processes. (0.63)

Item 18: Most decisions taken around here are based on a thorough reflection of possible solutions. (0.63)
Item 14: Responsibilities are clearly demarcated in this department/, company. (0.68)

Item 20: There are enough resources at my disposal to fulfil my tasks. (0.76)

Item 9: My manager offers help and guidance to improve my performance. (0.67)

Item 10: I am carefully informed about developments within the company that are relevant to my work. (0.73) 
Table 5. Factor 2: Manager's actions and support

\begin{tabular}{|c|c|}
\hline Sweden (2003) & Slovenia (2006) \\
\hline $\begin{array}{l}\text { Item 21: The manager solves problems in an adequate way. } \\
(0.56)\end{array}$ & $\begin{array}{l}\text { Item 21: The manager solves problems in an adequate way. } \\
(0.80)\end{array}$ \\
\hline Item 2: I feel that the manager trusts me. (0.85) & Item 2: I feel that the manager trusts me. (0.79) \\
\hline $\begin{array}{l}\text { Item 12: My manager ably promotes the interests of my } \\
\text { department/, team within the company. }(0.71)\end{array}$ & $\begin{array}{l}\text { Item 12: My manager ably promotes the interests of my } \\
\text { department/ team within the company. }(0.78)\end{array}$ \\
\hline $\begin{array}{l}\text { Item 15: The manager shows appreciation if I perform a } \\
\text { good job. }(0.74)\end{array}$ & $\begin{array}{l}\text { Item 15: The manager shows appreciation if I perform a } \\
\text { good job. (0.79) }\end{array}$ \\
\hline $\begin{array}{l}\text { Item 17: The manager will always support me in cases of } \\
\text { problems with others. }(0.70)\end{array}$ & $\begin{array}{l}\text { Item 17: The manager will always support me in cases of } \\
\text { problems with others. }(0.79)\end{array}$ \\
\hline $\begin{array}{l}\text { Item 6: My manager is well aware of whether I perform as } \\
\text { expected or not. }(0.77)\end{array}$ & $\begin{array}{l}\text { Item 5: Differences of opinion between people are cleared } \\
\text { up in an open and honest way around here. }(0.73)\end{array}$ \\
\hline $\begin{array}{l}\text { Item 9: My manager offers help and guidance to improve } \\
\text { my performance. }(0.75)\end{array}$ & $\begin{array}{l}\text { Item 8: In this department, company, employees are treated } \\
\text { with care. }(0.73)\end{array}$ \\
\hline $\begin{array}{l}\text { Item 19: If I do a good job, appreciation is clearly shown. } \\
(0.62)\end{array}$ & $\begin{array}{l}\text { Item 16: My manager quickly implements our ideas for } \\
\text { improvement of work processes. }(0.81)\end{array}$ \\
\hline
\end{tabular}

ordinates' perception of their managers' trust in them. The reasons for the differences in Factor 2 (Managers' action and support) between the Swedish and the Slovenian samples (five out of eight items were identical) are not empirically investigated, but may be due to socio-cultural factors.

Table 7 presents data generated from the three factors on the mean value and standard deviation for the Swedish and Slovenian samples. The content analysis of the formed factors revealed a similarity in Factor 2 between the Swedish and the Slovenian samples. Furthermore, the weight values were similar.

\section{Regression analysis}

A regression analysis was used to explore the relation between the obtained factors and dependent variable (trust).
By using factor values, this study produced the following linear model (table 8).

The coefficient of determination, $\mathrm{R}^{2}$, is statistically important. Subordinates' trust in managers can statistically be explained by the actions of the managers (table 7). For a deeper understanding of whether the generated factors, with the help of factor analysis, showed a causal connection between trust and management, this study carried out a regression analysis. Table 8 shows that in the Swedish study, factor 2 explained 76 per cent degree of the trust in managers $(\mathrm{p}<0.001)$. Factors 1 and 3 were insignificant. The regression analysis confirmed that managerial actions and support fostered trust. This result was also in agreement with the findings of the regression analysis of the Slovenian study, in which fac-

Table 6. Factor 3: Goals, development and achievements

\begin{tabular}{ll}
\hline Sweden (2003) & Slovenia (2006) \\
\hline $\begin{array}{l}\text { Item 3: I am well aware of the goals of my department/, team. } \\
(0.81)\end{array}$ & $\begin{array}{l}\text { Item 3: I am well aware of the goals of my department/, team. } \\
(0.84)\end{array}$ \\
$\begin{array}{ll}\text { Item 7: I agree with the goals of my department/, team. (0.81) } \\
\text { Item 7: I agree with the goals of my department/, team. (0.83) }\end{array}$ & $\begin{array}{l}\text { Item 1: Ideas and suggestions for improvement of work pro- } \\
\text { cesses are quickly implemented in this department/, company. } \\
\text { the company that are relevant to my work. (0.67) }\end{array}$ \\
$\begin{array}{ll}\text { Item 13: I feel at ease in criticising the performance of my } \\
\text { colleagues in a constructive way. (0.64) }\end{array}$ & $\begin{array}{l}\text { Item 18: Most decisions taken around here are based on thor- } \\
\text { ough reflection of possible solutions. (0.62) }\end{array}$ \\
\hline
\end{tabular}


Table 7. Descriptive statistics for the factors according to the factor analyses Sweden $(N=138)$ and Slovenia $(N=108)$

\begin{tabular}{lcccc}
\hline \multirow{2}{*}{ Factors } & \multicolumn{2}{c}{ Mean } & \multicolumn{2}{c}{ Standard deviation } \\
\cline { 2 - 5 } & Sweden & Slovenia & Sweden & Slovenia \\
\cline { 2 - 5 } & 2003 & 2006 & 2003 & 2006 \\
\hline Factor 1: Improvements & 2.85 & 3.97 & 0.77 & 0.87 \\
Factor 2: Managers' actions & 2.79 & 3.81 & 0.95 & 0.84 \\
Factor 3: Goals & 3.40 & 4.03 & 0.83 & 0.96 \\
\hline
\end{tabular}

Table 8. Regression analyses - Sweden $(N=138)$ and Slovenia $(N=108)$

\begin{tabular}{lcccccccc}
\hline Model & \multicolumn{3}{c}{ B } & \multicolumn{2}{c}{ B (SE) } & \multicolumn{2}{c}{ B } & \multicolumn{2}{c}{ Significance } \\
\hline Country & Swed & Slov & Swed & Slov & Swed & Slov & Swed & Slov \\
\hline (constant) & -.69 & 4.02 & 0.24 & 0.09 & & & 0.004 & 0.000 \\
Factor 1: & & & & & & & & \\
Improvements & 0.20 & 0.04 & 0.16 & 0.15 & 0.12 & 0.72 & 0.219 & 0.754 \\
Factor 2: Manager's actions & 0.95 & 1.03 & 0.13 & 0.11 & 0.72 & 0.89 & $0.000^{* *}$ & $0.000^{* *}$ \\
Factor 3: Goals & 0.08 & -0.15 & 0.11 & 0.13 & 0.05 & -0.08 & 0.497 & 0.261 \\
Control variable: & & & & & & & & \\
Management group & 0.06 & 1.27 & 0.23 & 0.42 & 0.02 & 1.27 & 0.788 & 0.031 \\
Control variable: & & & & & & & & \\
Other employees & 0.30 & 1.01 & 0.12 & 0.13 & 0.11 & 0.96 & $0.016^{*}$ & 0.00
\end{tabular}

Note on Sweden 2003:

$R^{2}=0.760 ;$ Adjusted $R^{2}=0.754 ; F=141.164$

$* *=p<0.001$

$*=p<0.05$

Note on Slovenia 2006:

$R^{2}=0.826 ;$ Adjusted $R^{2}=0.813 ; F=61.755$

$* *=p<.0 .001$

tor 2, managerial actions, explained 82 per cent of the degree of trust in managers $(\mathrm{p}<0.001)$.

Factors 1 and 3 were insignificant in both studies. The results from the Swedish and Slovenian studies were similar and confirmed the second hypothesis. Employees' trust is due to the actions of the manager. However, this factor of managers' actions is not identical in the two samples.

These results support the framework of initiating trustworthy behaviour that Whitener et al. (1998) have suggested. They have identified five managerial behaviours that may affect employees' trust in managers: (1) behavioural consistency, which refers to regularity over time and across situations. Tables 5 and 6 show that these aspects are implied in items nos. 1 and $17 ;(2)$ acting with integrity, which refers to attributions that affect employees' trust and implied in items nos. 2, 5, and 6; (3) sharing and delegation of control, refers to participation in decision-making, which may be associated with item no. 3 ; (4) openness of communication refers to the provision of accurate information, explanations for decisions, and openness, which are found in items nos. 8, 9, 12, 15, and 19; and finally (5) demonstrations of concern, which refers to the consideration for employees' needs and interests, actions that protect employees' interests, and the unwillingness to exploit others for the sake of self-interest. This study provides empirical support to Whitener et al. (1998), who suggest that managers who engage in these behaviours will increase the likelihood that their employees will trust them.

Biljsma and van de Bunt (2003) have identified five managerial actions that elicit trust in managers by subordinates: (1) monitoring performance. Table 5 shows that this aspect is implied in item no. 6; (2) guidance to improve individual performance, which is found in item no. 9; (3) support in case of trouble with others, which is found in item no. 9; (4) openness to ideas of subordinates and co-operation-related problem solving, which are aspects found in items nos. 5, 16, and 21. Appreciation of good work, however, was not significantly related to trust in managers in Biljsma and van de Bunt's (2003) study. In this present study, this kind of behaviour was 
related to trust and items no. 15 and 19 were part of the factor 2, which explained trust in Sweden and Slovenia.

Item no. 21 (The manager solves problems in an adequate way) had the strongest correlation with the degree of trust (+ $0.82)$ in the Swedish sample and $(+0.86)$ in the Slovenian one. Dirks and Ferrin (2002, p. 615) have stressed that "at present, research has not explored which practices have the strongest effect on trust". They (2002, p. 622) have also stated: "Given this pattern of results, one might speculate that future research and practice might have greater success by focusing on leader behaviours and practices". The reasons for subordinates' trust in managers were quite similar. However, socio-cultural contexts appeared to influence what kinds of actions enhanced subordinates' trust in managers. This investigation has shown that Swedish and Slovenian managers' behaviours explain why subordinates trust them. Ferrin and Gillespie (2010) have also concluded that there is a considerable support for the view that there are both culturally specific and universally applicable determinants of trust.

Testing hypothesis 3: Trust in managers differs between the closest subordinates and other employees.

Table 9 shows the degree of trust per managerial group of 2003 in Sweden. It is evident that the closest subordinates had a higher degree of trust in their managers than all other employees had for one manager (average scores 3.3 versus 2.6). The closest subordinates of this manager also had more trust in the manager than all other subordinates had for the same manager. In the regression analysis for 2003 (table 8), a control was carried out to see if different managerial positions had an impact on the degree of trust. One group consisted of the closest subordinates of all eight managers $(\mathrm{N}=44)$, whilst the other group consisted of the other subordinates of one manager $(\mathrm{N}=94)$. A t-test showed that there was a significant difference in the degree of trust vested in the managers by their closest subordinates compared to the trust that other subordinates had, with $\mathrm{t}=3.118, \mathrm{p}<0.05$. In the Swedish sample the closest subordinates' trust in managers was higher than other employees'.

The hypothesis also received support from the analysis of the Slovenian sample. On the basis of the answers of 51 respondents directly subordinate to all managers (of which there were 25 close co-workers) and 57 other employees (108 respondents) in the Slovenian study, the following results refer to the statements connected to the individual factors originating from the factor analysis (table 7). The high degree of trust in Slovenian managers can be attributed to the respondents' proximity to the managerial level. In the Slovenian study, these respondents were the closest co-workers of the managers. In the Swedish case, however, respondents were more dispersed. This finding indicates that the degree of trust in managers declines as the hierarchical distance from the manager increases.

The Slovenian sample also throws some additional light on the importance of distance between the trust in managers and their subordinates (table 9). The Slovenian sample provides data on three levels whilst the Swedish sample provides two (i.e., the closest subordinates and other subordinates). A t-test on the average degree of trust between the 25 closest subordinates to the managers and the 57 most remote subordinates (lowest level) showed that this difference was significant, with $\mathrm{t}=4.106, \mathrm{p}<0.05$. Testing the average degree of trust between the 25 closest subordinates to the managers compared to the degree of trust of the 26 other subordinates reporting directly to the managers showed that this difference is insignificant, with $\mathrm{t}=0.405, \mathrm{p}>0.10$. Finally, a t-test of the differences in trust between the 26 subordinates reporting directly to the managers and the 57 other subordinates showed that this difference was significant, with $\mathrm{t}=2.569, \mathrm{p}<0.01$. The Slovenian study confirmed the result from Sweden: the more removed subordinates were from managers, the less they trusted them, a finding that supports the third hypothesis. These findings thus suggest that societal factors do not exert a strong influence.

\section{Conclusions}

Both of these studies show that managers enjoy different degrees of trust from their subordinates. The first hypothesis was supported. The level of trust vested in Slovenian manag-

Table 9. Descriptive statistics - Trust variables Sweden and Slovenia

\begin{tabular}{lcccccc}
\hline & \multicolumn{2}{c}{ Respondents (N) } & \multicolumn{2}{c}{ Average } & \multicolumn{2}{c}{$\begin{array}{c}\text { Standard } \\
\text { deviation }\end{array}$} \\
\cline { 2 - 7 } & Sweden & Slovenia & Sweden & Slovenia & Sweden & Slovenia \\
\hline $\begin{array}{l}\text { All managers - } \\
\text { closest subordinates }\end{array}$ & 44 & 25 & 3.25 & 4.4 & 1.241 & 0.666 \\
$\begin{array}{l}\text { All managers - subordinates } \\
\text { reporting directly }\end{array}$ & $\mathrm{NA}$ & 26 & $\mathrm{NA}$ & 4.29 & $\mathrm{NA}$ & 1.210 \\
$\begin{array}{l}\text { All managers - remote } \\
\text { Subordinates }\end{array}$ & $\mathrm{NA}$ & 57 & $\mathrm{NA}$ & 3.56 & $\mathrm{NA}$ & 1.180 \\
$\begin{array}{l}\text { One manager - remote } \\
\text { employees (Sweden only) }\end{array}$ & 94 & $\mathrm{NA}$ & 2.60 & $\mathrm{NA}$ & 1.212 & $\mathrm{NA}$ \\
\hline
\end{tabular}


ers by their subordinates is significantly higher than what is vested in Swedish managers. This study did not explore the reasons for this difference, but it may be due to the greater remoteness to power in Sweden.

The analysis revealed a degree of similarity regarding the managers' actions and support between the Swedish and the Slovenian samples, as five out of eight items were identical. Socio-cultural contexts may explain why the items in the factor "managers' actions and support" were not identical. The second hypothesis was partly supported. The actions of managers were decisive for the development of trust.

The actions and support of Swedish managers explained 76 per cent of the degree of trust that the subordinates had in them. This result is also in agreement with the findings of the Slovenian study, where managerial actions explained 82 per cent of the degree of subordinates' trust. These results may imply that both Swedish and Slovenian subordinates perceived leadership through managerial actions. Trust was strongly associated with such terms as "the manager has confidence in me", "the manager promotes our interests", "the manager shows me appreciation", "the manager supports me", and "the manager solves problems". In both these national samples the other two factors were insignificantly related to trust.

Trust in managers differed between the closest subordinates and other employees. The Swedish study supported the third hypothesis, since the closest subordinates had a significantly higher degree of trust in their manager than more remote subordinates. The Slovenian data also supported this conclusion. Theoretical explanations for these empirical outcomes in both the Swedish and Slovenian samples are hard to find.

\section{Implications for managers}

The development and maintenance of trust are especially important to managerial and organizational effectiveness, as several scholars (e.g., Atkinson, 2004) have emphasized. This comparative study of why Swedish and Slovenian subordinates trusted their managers informs managers on how to establish, maintain or increase the trust of their subordinates. The answer points to the subordinates' perception of their managers' actions. The manager needs to show in action that he or she trusts his or her subordinates, promotes the interests of the subordinates, demonstrates an appreciation of his or her subordinates, and solves problems in an adequate way. The comparative study also indicates that it is more difficult for managers to gain the trust of the more remote subordinates than of those who are closer.

\section{Implications for trust theory}

This comparative study of subordinates' reasons for trusting their managers in Sweden and Slovenia addresses four theoretical aspects of trust relations between managers and subordinates. It supports previous research and the assumptions that: (1) managers enjoy different degrees of trust; (2) trust is induced through actions; and (3) trust in managers differs between the closest subordinates and other employees. A strong association was found between the actions of managers and the degree of subordinates' trust in managers. The kind of leadership that generates trust is leadership by actions, or what are perceived as actions by the subordinates. Trust in managers is a promising way of enhancing organizational performance.

\section{References}

Andersen, J.A. (2005). Trust in managers: a study of why Swedish subordinates trust their managers. Business Ethics - A European Review, 14(4), 392-404, http://dx.doi: .org/10.1111/j.14678608.2005.00420.x

Atkinson, S. (2004). Senior management relationship and trust: an exploratory study. Journal of Managerial Psychology, 19(6), 571-587, http://dx.doi.org/doi:10.1108/02683940410551499

Atkinson, S. \& Butcher, D. (2003). Trust in managerial relationships. Journal of Managerial Psychology, 18(4), 282-304, http:// dx.doi.org/doi:10.1108/02683940310473064

Bagozzi, R.P. (1994). Measurement in marketing research: Basic principles of questionnaire design. In: Bagozzi, R.P. (ed.). Principles of marketing research (pp. 1-49), Cambridge, MA.: Blackwell.

Barney, J.B. \& Hansen, M.H. (1994). Trustworthiness as a source of competitive advantage. Strategic Management Journal, 15(8), 175-190, http://dx.doi.org/10.1002/smj.4250150912

Bass, B.M. (1990). Bass \& Stogdill's handbook of leadership. New York: Free Press.

Bhattacharya, R., Devinney, T.M. \& Pillutla, M.M. (1998). A formal model of trust based on outcomes. Academy of Management Review, 23, 459-472, http://dx.doi.org/10.5465/ AMR.1998.926621

Bigley, G.A. \& Pearce, J.L. (1998). Straining for shared meaning in organization science: Problems of trust and distrust. Academy of Management Review, 23, 405-421, http://dx.doi.org/10.5465/ AMR.1998.926618

Bijlsma-Frankema, K. (2000). Correlates of trust in a general hospital. In: Rahim, A. Golembiewski, R.T. \& Mackenzie, K.D. (eds.). Current topics in management, pp. 141-166. Greenwich, CT: JAI Press.

Bijlsma-Frankema, K. (2002). Enabling organisational learning and trust in top management: Case of a mental health care organisation. Proceedings, Workshop on Trust. Brussels: EIASM.

Biljsma, K.M. \& van de Bunt, G. (2003). Antecedents to trust in managers: a 'bottom-up' approach. Personnel Review, 32, 638-664, http://dx.doi.org/10.1108/00483480310488388

Bijlsma-Frankema, K., de Jong, B. \& van de Bunt, G.G. (2008). Heed, a missing link between trust, monitoring and performance in knowledge intensive teams. The International Journal of Human Resource Management, 19(1), 19-40, http://dx.doi. org/10.1080/09585190701763800

Coleman, J.S. (1990). Foundations of social theory, Cambridge, MA.: Harvard University Press.

Dirks, K.T. (2000). Trust in leadership and team performance: Evidence from NCAA Basketball. Journal of Applied Psychology, 85, 1004-1012, http://dx.doi.org/10.1037/00219010.85.6.1004

Dirks, K.T. \& Ferrin, D.L. (2002). Trust in leadership: Metaanalytic findings and implications for research and practice. Journal of Applied Psychology, 87(4), 611-628, http://dx.doi. org/10.1037/0021-9010.87.4.611

Dirks, K.T. \& Skarlicki, D.P. (2004). Trust in leaders: Existing research and emerging issues. In: Kramer, R.M. \& Cook, K.S. (eds.), Trust and distrust in organizations, pp. 21-40, New York: Russell Sage.

Doney, P.M., Cannon, J.P. \& Mullen, M.R. (1998). Understanding the influence of national culture on the development of trust. 
Academy of Management Review, 23, 601-620. http://dx.doi org/10.5465/AMR.1998.926629

The Edelman Trust Barometer (2009), Retrieved March 2010, from http://www.edelman.com, trust, 2009.

Elangovan, A.R., Auer-Rizzi, W. \& Szabo, E. (2007). Why don't I trust you now? An attributional approach to erosion of trust Journal of Managerial Psychology, 22(1), 4-24. http://dx.doi. org/10.1108/02683940710721910

Ferrin, D.L. \& Gillespie, N. (2010). Trust differences across nationalsocietal cultures: much to do, or much ado about nothing? In: Sauders, M., Skinner, D. Dietz, G., Gillespie, N. \& Lewicki, R.J. (eds.), Organizational trust. A cultural perspective, (pp. 42-86). Cambridge:Cambridge University Press, http://dx.doi. org/10.1017/CBO9780511763106.003

Fleishman, E.A. \& Harris, E.F. (1962). Patterns of leadership behavior related to employee grievances and turnover. Personnel Psychology, 15(1). 43-56, http://dx.doi. org/10.1111/j.1744-6570.1962.tb01845.x

Gambetta, D. (1988). Can we trust trust? In: Gambetta, D. (ed.) Trust: Making and breaking co-operative relations (pp. 213 237). Oxford: Basil Blackwell,.

Halman, L. (2003). The European values study: The third wave. Source book of the 1999-2000 European values study survey. Tilburg: Tilburg University.

Hofstede, G. (1991). Cultures and organizations. London: McGrawHill.

Hofstede, G. \& Hofstede, J.G. (2004). Cultures and organizations: Software for the mind. New York: McGraw-Hill.

House, R.J., Hanges, P.J., Javidan, M., Dorfman, P.W. \& Gupta, V. (eds.) (2004). Culture, leadership, and organizations. The GLOBE study of 62 societies, Thousand Oaks, CA: Sage.

Joseph, E.E. \& Winston, B.E. (2005). A correlation of servant leadership, leader trust, and organizational trust. Leadership \& Organizational Development Journal, 26(1): 6-21. http:// dx.doi.org/10.1108/01437730510575552

Luhmann, N. (1988). Familiarity, confidence and trust: problems and alternatives. In: Gambetta, D. (ed.), Trust: Making and breaking co-operative relations (pp. 213-237). Oxford: Basil Blackwell.

Lämsä, A-M. \& Pucetaite, R. (2006). Development of organizational trust among employees from a contextual perspective. Business Ethics: A European Review, 15(2), 130-141, http://dx.doi. org/10.1111/j.1467-8608.2006.00437.x

Mayer, R.C., Davis, J.H. \& Schoorman, F.D. (1995). An integrative model of organizational trust. Academy of Management Review, 20, 709-734, http://dx.doi.org/10.2307/258792

Morgan, D.E. \& Zeffane, R. (2003). Employee involvement, organizational change and trust in management. International Journal of Human Resource Management, 14(1), 55-75. http://dx.doi. org/10.1080/09585190210158510
Nunally, J.C. (1978). Psychometric theory. New York: McGraw-Hill. Poon, J.M.L. (2006). Trust-in-supervisor and helping coworkers: moderating effect of perceived politics. Journal of Managerial Psychology, 21(6), 518-532. http://dx.doi. org/10.1108/02683940610684373

Rousseau, D.M., Sitkin, S.B., Burt, R.S. \& Camerer, C. (1998). Not so different after all: a cross-discipline view of trust. Academy of Management Review, 23, 393-404. http://dx.doi.org/10.5465/ AMR.1998.926617

Rus, A. \& Iglič, H. (2005). Trust, governance and performance: the role of institutional and interpersonal trust in SME development. International Sociology, 20, 371-391, http://dx.doi. org/10.1177/0268580905055481

Seligman, A.B. (1997). The problem of trust. Princeton, NJ. Princeton University Press.

Sitkin, S.B. \& Roth, N.L. (1993). Explaining the limited effectiveness of legalistic "remedies" for trust, distrust. Organization Science, 4, 367-403, http://dx.doi.org/10.1287/orsc.4.3.367

Sheppard, B.H. \& Sherman, D.M. (1998). The grammars of trust: a model and general implications. Academy of Management Review, 23, 422-437, http://dx.doi.org/10.2307/259287

van Deth, J.W., Montero, J.R. \& Westholm, A. (eds.) (2007). Citizenship and Involvement. In: European democracy. A comparative analysis (pp 66-87), London: Routledge.

Wade, M.D. (2003). Differences in values, practices, and systems among Hungarian managers and Western expatriates. Journal of World Business, 38, 224-244.

Whitener, E.M., Brodt, S.E., Korsgaard, M.A. \& Werner, J.M. (1998). Managers as initiators of trust: An exchange relationship framework for understanding managerial trustworthy behavior. Academy of Management Review, 23, 513-530, http://dx.doi. org/10.2307/259292

Wicks, A.C. \& Berman, S.L. (2004). The effects of context on trust in firm - stakeholder relationships. Business Ethics Quarterly, 14(1), 141-160, http://dx.doi.org/10.5840/beq20041411

Jon Aarum Andersen is professor of Business Administration (management) at Linnaeus University, Sweden (partly leave of absence) and full time professor of Organization and Leadership at Lillehammer University College, Norway.

Jure Kovač is a Professor of Organization and Management at Faculty of Organizational Sciences, University of Maribor. His research interests are organization theory, organization design and management development. 